\title{
LA BÚSQUEDA DE UN NUEVO MODELO DE RELACIONES CON LOS TERRITORIOS ULTRAMARINOS DURANTE EL TRIENIO LIBERAL (1820-1823)
}

\author{
POR \\ AGUSTÍN SÁNCHEZ ANDRÉS \\ Colegio de México
}

\begin{abstract}
El autor plantea el estudio de los mecanismos de respuesta del régimen constitucional frente a la quiebra definitiva del modelo colonial tradicional entre 1820 y 1823 . Ello permite profundizar en la naturaleza del nuevo modelo de relaciones establecido por el régimen liberal con los restos del imperio colonial durante el primer tercio del XIX.
\end{abstract}

\section{EL LIBERALISMO Y LA CRISIS DEL MODELO COLONIAL TRADICIONAL.}

Entre 1808 y 1823 la crisis del sistema colonial español se superpuso al desmoronamiento del Antiguo Régimen en la Península y al planteamiento por el liberalismo emergente de modelos alternativos de organización política, social y económica. Entre dichos modelos se encontraban las bases teóricas de una nueva política colonial.

El hundimiento del sistema colonial español fue afrontado por la mayoría liberal de las Cortes de Cádiz mediante un intento de asociar a las colonias al nuevo modelo de Estado que se estaba gestando en la Península. La fórmula utilizada para ello fue la extensión mati-

\footnotetext{
SIGLAS UTILIZADAS

A.H.N.: $\quad$ Archivo Histórico Nacional, Madrid

A.M.A.E.: F, Archives del Ministère des Affaires Etrangèred, París

D.A.D.C.: Diario de las Actas y Discusiones de las Cortes durante la legislatura de los años 1820 y 1821

D.S.C.: Diario de Sesiones de Cortés. Congreso

A.G.I.: $\quad$ Archivo General de Indias, Sevilla
} 
zada del nuevo sistema político de carácter representativo a las colonias. Este extremo aseguraba a los territorios ultramarinos una participación considerable dentro del proceso de toma de decisiones metropolitano, caracterizado por el predominio del Poder Legislativo.

Sin embargo, la existencia de marcadas diferencias entre la metrópoli y las colonias hacía imposible una extensión plena del modelo organizativo metropolitano a las mismas. En este sentido, entre 1810 y 1814 se desarrollaron intensos debates en el seno de las Cortes, que tuvieron por objeto determinar los términos concretos en que tendría lugar la participación de las colonias en el nuevo sistema político y la propia posición jurídico-política de las mismas en el nuevo Estado liberal.

El proceso de discusión en torno a los diversos sistemas de representatividad colonial planteados y discutidos en las Cortes de Cádiz ha sido estudiado por A.F. Zimmerman, D. Ramos y M.L. Riau1. Ambos historiadores coinciden en que dicho debate se saldó con la aprobación de una fórmula consensual entre los diputados americanos y metropolitanos. La expresión final de dicha fórmula estaría constituída por el Real Decreto de 15 de octubre de 1810, que reconocía el derecho de las colonias a una representación proporcional y que sería recogido finalmente por el Título III y el art.29 de la Constitución de 1812.

Sin embargo, dicho debate no puede estudiarse al margen del proceso de discusión entablado paralelamente, tanto en torno al sentido de la soberanía nacional, cuyo resultado serían los arts.1, 5 y 18 de la Constitución Gaditana, como en torno al nuevo modelo de organización político-administrativa del mundo colonial, plasmado finalmente en la Instrucción para el Gobierno político-económico de las provincias y en el art. 222 del mencionado Texto constitucional.

La falta de un verdadero consenso en torno a la primera de estas cuestiones determinaría la inviabilidad práctica de la política colonial ensayada por las Cortes de Cádiz.

En este sentido, tanto J. Lynch como T. Halperin, han sugerido que la aparición de un difuso sentimiento nacional americano cons-

\footnotetext{
1 A.F. Zimmerman: "Spain and its Colonies, 1808-1820", en Hispanic American Historical Review, $\mathrm{n}^{\circ}$ 11, (1931), pp.439-463; D. RAMOS:"Las Cortes de Cádiz y América", en Revista de Estudios Políticos, n ${ }^{\circ}$ 126, (1961), pp. 211-273; M.L. RiEU-MillaN :"Los diputados americanos en las Cortes de Cádiz. Elecciones y representatividad", en Quinto Centenario, $\mathrm{n}^{\circ} 14,(1988)$, pp. 53-73.
}

R. I., $1997, \mathrm{n}^{\circ} 210$ 
tituyó una fase necesaria dentro del proceso de búsqueda de legitimidad por las juntas americanas, desde el momento en que éstas hubieron de enfrentarse abiertamente a los depositarios de la legalidad anterior, apoyados por el viejo aparato político-administrativo y por una impotente metrópoli ${ }^{2}$.

La mayoría liberal de las Cortes de Cádiz no supo o no pudo llegar a un consenso con las élites coloniales insurgentes en torno a esta cuestión. Como señala M. Marliani, ello sólo hubiera sido posible a través de un acuerdo que garantizara a las mismas la hegemonía política y social que exigían en sus respectivas zonas de influen$\mathrm{cia}^{3}$. El apoyo liberal a la facción peninsular en el proceso de confrontación que se desarrollaba en América impidió cualquier acuerdo con los sectores oligárquicos criollos y empujó a éstos a una ruptura abierta con la metrópoli como única solución, haciendo inútil el desarrollo del nuevo modelo de relaciones colonias-metrópoli planteado por el régimen liberal.

Una década más tarde, la restauración del régimen constitucional permitió la continuación del debate colonial sobre nuevas bases. Ello fue posible por la radicalización de un importante sector del liberalismo durante esta etapa. Extremo que ha sido resaltado por algunos de los principales estudiosos del período, como C.W. Fehrenback o A. Gil Novales ${ }^{4}$. Dicha radicalización se extendería al campo de la política colonial marcando un giro cualitativo respecto a las soluciones planteadas por las Cortes de Cádiz.

En este sentido, T. Halperin ha visto en la nueva actitud del liberalismo español uno de los detonantes de la creciente desafección de los realistas americanos hacia la metrópoli, ya que estos sectores eran conscientes de ser las víctimas propiciatorias de cualquier posible acuerdo de la metrópoli con las élites criollas insurgentes 5 . En la misma línea incide J. Lynch, para quien una de las principales cau-

2 J. LYNCH: Las revoluciones hispanoamericanas. 1808-1826, Barcelona, Ariel, 1983, pp. 15-47;

3 T. HALPERIN: Historia Contemporánea de América Latina, Madrid, Alianza, 1969, pp. 89-102.

4 M. MARLIANI: El reinado de Fernando VII, Madrid, Anthropos, 1986, pp. 34-39.

5 A. GIL Novales: El Trienio Liberal, Madrid, Alianza, 1982, pp. 20-23; C.W. FEHRENBACK: "Moderados and exaltados: the liberal opposition to Ferdinand VII, 18141823", en Hispanic American Historical Review, n 50, (1970), pp. 52-69. 
sas del desarrollo de la última fase del proceso de independencia americano, sería el intento del régimen liberal metropolitano de aplicar a las colonias reformas similares a las que se planteaban para la metrópolí6. Más recientemente, B.G. Silvestrini, L.W. Bergard, L.R. Jensen y C. Pumar, entre otros especialistas, han apreciado, más o menos matizadamente, la existencia de un giro en la política colonial española durante el Trienio?.

Otros historiadores, por el contrario, consideran que la política colonial desarrollada durante el Trienio fue una mera continuación de la política ultramarina de las Cortes de Cádiz. En este sentido se manifiestan J. Navarro, M. P. Costeloe, A. García Ochoa, y J. Domínguez ${ }^{8}$.

Por nuestra parte, consideramos que la política colonial del Trienio atravesó dos períodos perfectamente definidos. Durante una primera etapa, que se extendería hasta mayo de 1821 , la política colonial de los gobiernos liberales se caracterizó por su continuidad respecto a las políticas coloniales de carácter integrador ensayadas entre 1812 y 1814 . Sin embargo, a partir del Gobierno Bardaxí-Feliú tuvo lugar el planteamiento e incluso la aprobación de algunos de los modelos alternativos de organización colonial que habían sido rechazados entre 1812 y 1814.

El restablecimiento de la Constitución de Cádiz en marzo de 1820 había supuesto que los territorios ultramarinos volvieran a revestir el carácter de partes integrantes de pleno derecho de la Nación española, condición que les había sido conferida por el art. 1 del Texto de 1812. Para Christiansen, la burguesía mercantil de Cádiz y la incipiente burguesía industrial catalana esperaban con esta medida atraer de nuevo a las colonias a la órbita española. Este objetivo hizo

6 HALPERIN, [3] p. 109.

7 B.G. SILVESTRINI: Historia de Puerto Rico. Trayectoria de un pueblo, Río Piedras, UPR, 1990, pp. 233-234; L.R. JENSEN: Children of colonial despotism. Press, Politics and Culture in Cuba. 1790-1840, Tampa, Florida University Press, 1988, p. 306; C. PUMAR:"La primera gran renuncia española al colonialismo: $1820 \mathrm{o}$ el retorno de los patriotas americanos", en Estudios de Historia Social y Económica de América, n 12, (1995), pp. 133-141.

8 J.R. NAVARRO: Entre esclavos y constituciones. El colonialismo liberal de 1837 en Cuba, Sevilla, CSIC, 1991, p. 26; J. DOMINGUEZ: Insurrección o lealtad. La desintegración del imperio español en América, México, FCE, 1985, pp. 237-239; A. GARCIA OCHOA: La política española en Puerto Rico durante el siglo XIX, Río Piedras, Universidad de Puerto, 1982, p. 85; M.P. COSTELOE: La respuesta a la independencia. La España imperial y las revoluciones hispanoamericanas. 1810-1840, México, FCE, 1989, pp. 20-21.

R. I., $1997, \mathrm{n}^{\circ} 210$ 
de ambos grupos unos de los promotores más directos de la conspiración liberal de $1820^{9}$.

Sin embargo, hacia 1820 dicho objetivo no respondía a la realidad. En este punto coincidimos con Lynch cuando afirma que la política represiva practicada entre 1814 y 1819, pese a los efímeros éxitos militares conseguidos, había supuesto la desaparición de cualquier solución a la crisis colonial que no pasara por el reconocimiento de la independencia de la mayoría de dichos territorios ${ }^{10}$. La evolución posterior de los hechos demuestra que este extremo no fue percibido por las élites políticas metropolitanas, sumidas en las dificultades derivadas de la resistencia a la implantación del modelo liberal en la propia Península.

Paralelamente la Revolución de 1820 precipitó el proceso emancipador americano al enajenar el apoyo a la metrópoli de las oligarquías coloniales más conservadoras, que, desde 1810, habían constituído el principal y casi único soporte de la Corona en América.

Ambos factores ponían de manifiesto el fracaso de la fórmula ensayada entre 1812 y 1814, basada en la plena extensión a las colonias del sistema político-administrativo metropolitano. Ello determinó que entre 1821 y 1823 tuviera lugar el planteamiento de un modelo de organización colonial sumamente descentralizado, que respondiera parcialmente a la particular idiosincrasia de las colonias.

Desde esta óptica, el nuevo régimen liberal se planteó el desarrollo de dos posibles modelos de relaciones entre la metrópoli y los territorios ultramarinos.

Por una parte, se intentó vincular a los nuevos estados americanos con la metrópoli a través de una unión de carácter dinástico. Este extremo sólo tuvo ciertas posibilidades de éxito en el caso del antiguo Virreinato de la Nueva España, donde la disposición de amplios sectores de la oligarquía colonial a un acuerdo de este tipo, llevaría a un importante sector de las Cortes a defender la adopción de una fórmula de carácter confederal.

Por otra parte, en el caso de las colonias antillanas y asiáticas, se ensayó la construcción de un marco político-administrativo particular que respondiera a las diferentes condiciones de los territorios ul-

9 J. ChristiAnSEN: Los orígenes del poder militar en España, 1808-1854, Madrid, Cisneros, 1944, p. 98.

10 LYNCH, [2] pp. 89-90. 
tramarinos que restaban a España y, en definitiva, evitara su incorporación al proceso general de emancipación de las colonias españolas en América.

EL FRACASO DE LOS PROYECTOS DE CONSTITUCIÓN DE UNA CONFEDERACIÓN DE REINOS HISPÁNICOS.

La restauración del régimen constitucional en España produjo un consenso político dentro del bloque oligárquico hispano-mexicano en torno a la necesidad de una separación pacífica de México ${ }^{11}$. En la adopción de dicho consenso tuvo un papel especialmente activo el alto clero colonial, de mayoría peninsular, que se sentía amenazado por los decretos anticlericales del Trienio ${ }^{12}$. En este sentido, sería el propio jefe del ejército realista, el coronel Iturbide, quien el 22 de febrero de 1821 proclamaba en Iguala la independencia de México. En los días siguientes la mayoría del ejército realista y de los cabildos de las principales ciudades mexicanas se pronunciaban a favor del movimiento independentista, de manera que, a mediados de marzo, solo Veracruz y Acapulco continuaban bajo la autoridad del virrey Apodaca.

El consenso de los diversos sectores de la oligarquía mexicana en torno a la independencia tuvo su expresión en el denominado Plan de Iguala. En virtud del mismo se establecía la creación de un imperio mexicano independiente de España, cuyo trono se ofrecía sucesivamente a Fernando VII, a uno de sus hermanos o a "otro individuo de casa reinante que designare el Congreso" 13 .

Paralelamente al desarrollo de este proceso, los diputados mexicanos ante las Cortes españolas, presionaron al Gobierno metropolitano con el objetivo de llegar a algún tipo de acuerdo que tuviera como base el Plan de Iguala. Ello se debía al hecho de que los dipu-

11 B.R. HAMNET: Revolución y contrarevolución en México y Perú. Liberalismo, realeza y separatismo, México, Siglo XXI, pp. 181-182.

12 J.M. BREEDLOVE: "Effect of the Cortes, 1810-1822, on Church Reform in Spain and México", en N.L. BENSON (ed.): México and the Spanish Cortes, 1810-1822, Austin, University of Texas Press, 1966, pp. 125-131.

13 A. MATUTE: México en el siglo XIX. Antología de fuentes e interpretaciones históricas, México, UAM, 1973, pp. 227-230.

R. I., 1997, n. $^{\circ} 210$ 
tados mexicanos eran, ante todo, los representantes de los intereses de los grandes propietarios y comerciantes criollos y peninsulares, extremo que venía determinado por su designación en 1820 por los cabildos de las principales ciudades de la colonia.

En este sentido, el 4 de mayo, el Gobierno establecía una Comisión de Ultramar, compuesta por diputados españoles y mexicanos, para que estudiara esta cuestión que, en caso de resolverse positivamente, podría extenderse a las relaciones de la metrópoli con los restantes territorios de Ultramar ${ }^{14}$.

Con este objeto, el 16 de mayo la Comisión de Ultramar se reunía con una Comisión Especial, nombrada por las Cortes e integrada por antiguos virreyes, capitanes generales e intendentes coloniales residentes en Madrid. En esta reunión, presidida por el ministro interino de Gobernación de Ultramar, se acordaba el establecimiento de un nuevo modelo de relaciones entre la metrópoli y las antiguas colonias.

El proyecto aprobado por la Comisión Mixta establecía la creación de tres grandes imperios en las colonias americanas: uno en el norte, que comprendería la mayoría del Virreinato de Nueva España, otro centrado en el Virreinato de Nueva Granada y la Capitanía General de Venezuela, y un tercero, cuyo ámbito espacial se extendería a los antiguos virreinatos de Perú y de La Plata, así como a la Capitanía General de Chile. Fernando VII reinaría en todos ellos a través de infantes que, en calidad de virreyes, gobernarían según el sistema constitucional existente en España. Este proyecto reconocía la independencia de facto de cada uno de dichos reinos, a los que se dotaba de órganos legislativos y judiciales propios, si bien no concretaba el alcance de las funciones de los virreyes como representantes del monarca.

Asímismo, la Comisión decidió asimilar las Filipinas al nuevo modelo de relaciones con los territorios de Ultramar, en tanto que $\mathrm{Cu}$ ba y Puerto Rico continuarían vinculadas directamente a la metrópoli,

\footnotetext{
14 La componían, por parte peninsular, el conde de Toreno, Yandiola, Calatrava y Crespo, en tanto que por parte de las colonias americanas estaba integrada por los diputados Alamán, Amati, Paúl y Fagoaga. C. VIllanueVA: Fernando VII y los nuevos estados, París, Librería Paul Ollendorf, 1923, p.59. La creación de esta comisión respondía a las presiones que el Consejo de Estado efectuó sobre el Gobierno entre enero y marzo de 1821 para que recuperara la iniciativa en América. Vid. A.H.N, Estado, lib. 22d.
}

R. I., $1997, \mathrm{n}^{\circ} 210$ 
pese a las presiones mexicanas para incluir dichas islas en su jurisdicción, rechazadas por los representantes antillanos en las Cortes ${ }^{15}$.

El proyecto, desvelado el día 21 por el periódico El Espectador, contó con el apoyo de los círculos liberales más radicales ${ }^{16}$. En este sentido se pronunciaban los diputados Núñez y Adán, en el curso de un intenso debate que tuvo lugar durante la noche del 21 al 22 de mayo en la sociedad patriótica que se reunía en La Fontana de Oro ${ }^{17}$.

No obstante, la incertidumbre frente al desarrollo de los acontecimientos en América, el dictamen negativo del Consejo de Estado, que ponía en duda la constitucionalidad del proyecto, y la firme oposición de Fernando VII, que se escudaba en dicha resolución, provocaron dudas en el Gobierno acerca de la conveniencia de plantear o no este proyecto a las Cortes, que motivaron finalmente su archivamiento.

Sin embargo, el debate político acerca de las medidas que debían adoptarse ante la crisis colonial continuó en las propias Cortes, avivado por el apoyo prestado por un sector de la prensa radical al proyecto planteado por las comisiones de Ultramar y Especial.

En este marco, el 4 de junio tenía lugar la comparecencia de los ministros ante las Cortes, para informar en sesión pública de las noticias oficiales enviadas por el virrey Apodaca, que revelaban la extensión alcanzada por la insurrección en México. En el curso de dicha sesión los diputados mexicanos, en clara sintonía con los sectores más conservadores de la oligarquía hispano-mexicana, declararon la inminencia de la separación de la Nueva España si las Cortes no aprobaban de inmediato las resoluciones adoptadas en el seno de la Comisión Mixta.

En este sentido se manifestaba Juan Esteban Milla, quien consideraba que el Gobierno debía proponer a Iturbide una inmediata suspensión de hostilidades en tanto se procedía a discutir la forma en que tendría lugar la separación de la colonia. Por su parte, Juan Gómez de Navarrete proponía que se comunicase a los insurrectos la disposición de las Cortes a hacer compatible la Constitución con las especiales características de los territorios de Ultramar. El diputado michoacano aseguraba que Iturbide no pretendía una separación absoluta

15 A.M.A.E, F, Espagne, 1821, leg. 712, notas del 18 y 19 de mayo de 1821.

16 El Espectador, Madrid, 21 de mayo de 1821.

17 A.M.A.E., F., Espagne, 1821, leg. 712, notas del 24 y 28 de mayo de 1821.

R.I., $1997, \mathrm{n}^{\circ} 210$ 
de España sino obtener para su país una sección de Cortes y una delegación del Ejecutivo propias. En tanto que José Mariano de Michelena anunciaba al Congreso la próxima presentación por los diputados de Ultramar de un proyecto de organización político-administrativa, de cuya aprobación dependería la conservación de dichos territorios ${ }^{18}$.

Dicha propuesta no fue presentada hasta el 25 de junio, momento en que el diputado José Miguel Ramírez, en representación de la totalidad de la diputación americana, presentaba a las Cortes un proyecto relativo al nuevo modelo de organización político-administrativa de los territorios ultramarinos ${ }^{19}$.

La propuesta presentada por Ramírez debe considerarse como producto del consenso político conseguido en torno a la independencia por los sectores peninsular y criollo de la oligarquía mexicana de los que los representantes mexicanos en las Cortes metropolitanas eran meros portavoces.

La propuesta de los parlamentarios mexicanos planteaba la creación de cuerpos legislativos independientes bajo la denominación de Secciones de Cortes, en cada una de las tres entidades políticas en que se dividiría el antiguo imperio español en América. Si bien, establecía una vinculación entre los legislativos coloniales y las Cortes metropolitanas, ya que, por una parte, se supeditaba el sistema de elección y el funcionamiento de estas cámaras a las normas establecidas por la Constitución para las Cortes españolas, en tanto que, por otra, se reservaban determinadas funciones de carácter general a las Cortes metropolitanas, como eran las relativas a la elección del monarca, la declaración de guerra y la firma de tratados internacionales de alianza ofensiva ${ }^{20}$.

18 D.A.D.C, Madrid, Imp. Minerva Española, 1821, vol. XX, 25 de junio, p. 42.

19 En el preámbulo a esta exposición el diputado Ramírez argumentaba que la distancia y los elevados gastos del viaje hacían inviable la presencia regular de los parlamentarios coloniales en las Cortes. En este mismo sentido el diputado mexicano señalaba acertadamente que la necesaria delegación del poder de las Cortes en las autoridades ejecutivas de la colonia hacía imposible la aplicación del marco constitucional. D.A.D.C, vol. XXIII, 25 de junio, pp. 22-25.

$20 \mathrm{El}$ art. 2 de la propuesta de Ramírez extendía a los legislativos coloniales todas las facultades concedidas a las Cortes metropolitanas por el art.131 de la Constitución, es decir se pedía para las Cámaras coloniales la potestad "para proponer y decretar las leyes e interpretarlas y derogarlas en caso necesario", así como competencia exclusiva en materia presupuestaria. D.A.D.C, vol. XX, 25 de junio, p. 22. 
El Poder Ejecutivo sería ejercido en cada una de las nuevas divisiones políticas por un gabinete, presidido por "un sugeto nombrado libremente por S.M. entre los más distinguidos por sus relevantes cualidades, sin que se escluyan las personas de la familia real" 21 . Este delegado real, que solo podría ser removido por el propio Rey, tendría el derecho de sanción y veto sobre la legislación emanada de los respectivos cuerpos legislativos coloniales, si bien estas leyes, provisionalmente en vigor, estarían sujetas a su vez a la ratificación de Fernando VII, quien podría revocarlas.

Paralelamente, se creaban tres secciones independientes del Consejo de Estado, en tanto que el Poder Judicial sería ejercido de forma independiente por los tribunales existentes en cada ámbito. En este sentido, se establecían tres secciones del Tribunal Supremo.

El proyecto no establecía un modelo de organización política confederal strictu sensu, pues no implicaba la creación de una macroestructura política común al conjunto. No obstante, la propuesta de Ramírez se aproximaba considerablemente a este extremo al contemplar la existencia de una institución común al frente del Poder Ejecutivo: la Corona española.

Tras intensos debates el proyecto fue aceptado por la mayoría parlamentaria. De esta manera el 26 de junio se presentaba a la aprobación de las Cortes un proyecto de ley que aplicaba la propuesta de Ramírez al caso de México, si bien se introducían algunas adiciones $^{22}$.

En este sentido, el art.10 declaraba libre el comercio entre México y España, estableciendo que "sería considerado como interior de una provincia á otra de la monarquía" y los arts.11 y 12 establecían una contribución mexicana de 200 millones de reales, dedicada al pago de la deuda extranjera. Por otra parte, el art.13 ampliaba el compromiso mexicano con el Tesoro de la Península al sostenimiento de parte de los gastos generados por la Casa Real, así como de otros gastos metropolitanos de carácter general.

La disolución de las Cortes el 30 de junio impidió que dicha propuesta llegara a ser debatida y votada por la Cámara. Poco después, el nuevo virrey de Nueva España, O'Donojú, se veía obligado por la

21 D.A.D.C, vol. XX, 25 de junio, p. 23.

22 D.A.D.C, vol. XX, 26 de junio de 1821, p. 4-7.

R. I., $1997, \mathrm{n}^{\circ} 210$ 
presión de los elementos peninsulares a reconocer la independencia de México.

El Tratado de Córdoba, firmado el 24 de agosto de 1821, hacía inviable la discusión del Proyecto Ramírez en el seno de las Cortes Extraordinarias, reunidas el 30 de septiembre de ese año. Máxime cuando el 16 de septiembre la Capitanía General de Guatemala seguía el ejemplo mexicano declarando igualmente la independencia.

El proyecto Ramírez sería recuperado tardíamente con ocasión del envío de una comisión parlamentaria a San Juan de Ulúa en enero de 1822 , con el objetivo de llegar a un imposible acuerdo con el Gobierno mexicano ${ }^{23}$. Estancadas las negociaciones la comisión propuso la creación de una confederación de naciones independientes: la_Confederación Hispanoamericana.

El proyecto de constitución de dicha confederación fue presentado el 27 de enero por el diputado Golfín, si bien éste habría sido inspirado por Lucas Alamán, quien intentó hasta el último momento conseguir una independencia pactada con la metrópoli.

El nuevo proyecto presentado a la aprobación de las Cortes constaba de los siguientes puntos: el reconocimiento de la independencia de los nuevos estados americanos por España a cambio de una indemnización garantizada por determinadas plazas fuertes; el establecimiento de una alianza política y comercial permanente entre éstos y la metrópoli; la concesión de la totalidad de los derechos políticos a los ciudadanos de la Confederación, cualquiera que fuera el lugar de su residencia. Por último, el apartado 14 situaba al frente de la Confederación Hispanoamericana al Rey de España, con el título de "Protector de la Gran Confederación Hispano-Americana".

Las referencias a los órganos confederales eran muy imprecisas, pues el Proyecto se limitaba a convocar un Congreso Federal en Madrid dos años después de la aprobación del Proyecto. Dicho congreso estaría integrado por representantes de los diferentes estados de la Confederación y se limitaría a "tratar de los asuntos generales, sin perjuicio de las constituciones particulares de cada uno" 24 .

23 R.M. DE LABRA: América y la Constitución de 1812, Madrid, Sindicato de Publicidad, 1914, pp. 172-173.

24 D.S.C, 27 de enero de 1822, pp. 2023-2024.

R. I., $1997, \mathrm{n}^{\circ} 210$ 
En esta ocasión el proyecto fue rechazado por las Cortes. El grado de confusión en que la independencia mexicana había sumido a las Cortes y los propios problemas del régimen para afrontar la ofensiva de los elementos reaccionarios, que en el verano de 1822 habían conseguido tomar Urgel y formar una Regencia que pretendía gobernar en nombre del Rey, debió ser determinante en el rechazo de las Cortes a una solución, cuyas líneas maestras eran muy similares a las anteriores.

Tras el rechazo del proyecto Golfín, los últimos diputados mexicanos retornaron a su país. Poco después, en julio de 1822, Agustín de Iturbide era proclamado emperador de México.

\section{LOS INTENTOS DE CREACIÓN DE UN MARCO POLÍTICO-ADMINISTRATIVO} ESPECIAL EN LAS ANTILLAS.

El fracaso de las Cortes de Cádiz al intentar establecer un marco político-administrativo homogéneo en las colonias y la metrópoli, llevó al régimen liberal del Trienio a plantear la creación de un modelo de organización específico en aquellas colonias que no se habían sustraido al control de la metrópoli.

El primer paso en este sentido estuvo constituído por la exclusión de dichos territorios del nuevo modelo de organización políticoadministrativa implantado para todo el Estado por la Ley Gómez Becerra. Dicha ley revisaba en un sentido descentralizador la Instrucción para el gobierno económico-político de las provincias de 1813. Del ámbito de aplicación de la misma se excluía significativamente a los territorios ultramarinos. Este extremo suponía un giro respecto a la postura adoptada por las Cortes con anterioridad, pues la Instrucción de 1813 afectaba de la misma forma a la Península y a Ultramar.

Ello llevó a los representantes coloniales a solicitar la extensión del nuevo modelo de organización a las provincias ultramarinas en aplicación del art.10 de la Constitución, que sancionaba la uniformidad de la estructura político-administrativa del Estado, al extender la organización provincial a todos los territorios de la Monarquía. Este sentido tenía la proposición de ley presentada el 20 de mayo por el

R. I., $1997, \mathrm{n}^{\circ} 210$ 
diputado puertorriqueño José María Quiñones ${ }^{25}$. Sin embargo, la iniciativa de Quiñones fue desestimada por la Comisión de Diputaciones Provinciales.

\section{El Proyecto Quiñones.}

La negativa de las Cortes a extender a las colonias el modelo de organización provincial metropolitano implicaba el planteamiento de dos alternativas. Por una parte, el mantenimiento en Ultramar del modelo de organización colonial tradicional, lo que hubiera resultado incompatible con la extensión de la Constitución a dichos territorios y con la propia posición reformista adoptada por la mayoría liberal en esta materia. Por otra, la necesidad de crear un marco político-administrativo de carácter descentralizado específico para los territorios ultramarinos.

La mayoría de los diputados antillanos eran favorables a una solución del último tipo que constituyera el punto de partida hacia un modelo de organización autonómico. Este extremo puede deducirse tanto del análisis de los debates parlamentarios desarrollados a lo largo de todo el Trienio en relación con esta materia, como de la rapidez con la que el diputado puertorriqueño José María Quiñones presentó una nueva proposición reclamando un modelo de organización político-administrativa específico para las colonias, tan sólo nueve días después de haber sostenido la necesidad de extender el Proyecto Gómez Becerra a las mismas:

\footnotetext{
"En atención á que el proyecto que se ha presentado á la deliberación de las Cortes sobre el gobierno económico-político de las provincias no se estiende á las de Ultramar según lo propone la comisión que lo ha preparado, pido á las Cortes se sirvan encargar á la que está nombrada especialmente para entender en los asuntos de aquellos países, se ocupe desde luego en formar el que pueda convenir á las circunstancias de ellos con la posible brevedad" 26 .
}

La ambigüedad de los términos empleados en la propuesta anterior desaparecía del proyecto de organización colonial presentado

25 D.S.C, 20 de mayo de 1822, p. 1460.

26 D.S.C, 29 de mayo de 1822, p. 1614. 
por este mismo diputado el 10 de junio. En el preámbulo de dicho proyecto Quiñones defendía abiertamente la necesidad de establecer en Puerto Rico un sistema político-administrativo diferente al peninsular, justificado en la distancia, las dificultades de comunicación y las particulares necesidades de dichos territorios.

El diputado puertorriqueño José María Quiñones pertenecía a una antigua familia de hacendados de San Germán y había formado parte del Cabildo de San Juan, que apoyó su elección como diputado en 1820. Como tal representaba simultáneamente las aspiraciones de los propietarios criollos y de los comerciantes y funcionarios peninsulares residentes en esta ciudad. Hacia 1820 ello era posible, ya que, como señala D.M. Tirado, el grado de antagonismo existente entre ambas facciones de la élite colonial era aún muy reducido ${ }^{27}$.

El proyecto presentado por el diputado puertorriqueño se estructuraba en quince puntos que, en la parte que nos interesa, hacían referencia a la política presupuestaria y hacendística de la colonia y, especialmente, a las funciones asignadas a la diputación provincial puertorriqueña en estas materias.

El principal objetivo del proyecto radicaba en el establecimiento de un equilibrio presupuestario entre los gastos de la Administración colonial y los ingresos públicos generados en la isla. Para ello se proponían tres medidas: la congelación del gasto público en la colonia, la reforma del sistema impositivo existente en la isla y la creación de mecanismos locales de control presupuestario.

Si bien Quiñones delegaba en la correspondiente comisión de las Cortes la delimitación de las atribuciones concedidas a la diputación provincial en el terreno político, su propuesta suponía un primer paso hacia la constitución de un régimen político-administrativo específico para Puerto Rico. En el sentido de que, por una parte, entrañaba la extensión a la isla de determinados aspectos de la legislación aplicada con carácter general en la Península, y, por otra, exigía de la metrópoli un marco legislativo particular para su exclusiva aplicación en la colonia.

La conjugación de ambos aspectos, una aplicación parcial del corpus legislativo metropolitano y la aparición de una legislación de efecto privativo sobre la colonia había de traducirse en un sistema de

27 D. M. TIRADO: Las raices sociales del liberalismo criollo, Tesis de Maestría de la Universidad de Puerto Rico, 1992, en Colección Puertorriqueña, T. 596r, pp. 122-126.

R. I., $1997, \mathrm{n}^{\circ} 210$ 
organización político-administrativo distinto del metropolitano. Dicho sistema era asimilista, en cuanto a que aspiraba a un mayor grado de descentralización en determinados aspectos del proceso de toma de decisiones, pero excluía la participación directa de la colonia en el proceso de elaboración de las disposiciones, que, con carácter general o particular, afectaran a las colonias.

En este sentido, el proyecto concordaba con la voluntad reformista expresada por la mayoría liberal de las Cortes. Lo que posibilitó que la Cámara se comprometiera a una rápida tramitación de las medidas propuestas por Quiñones ${ }^{28}$. Tras una nueva lectura y discusión de las mismas se enviaron para su estudio a la Comisión de Negocios de Ultramar ${ }^{29}$. La cual, por el procedimiento de urgencia, emitía el 29 de junio un dictamen favorable al proyecto.

En dicho dictamen la Comisión de Ultramar refundía los quince puntos del proyecto de Quiñones en doce, añadiendo determinados aspectos y excluyendo solo de la nueva redacción la fiscalización de los bienes de los funcionarios de rentas ${ }^{30}$.

En el preámbulo al dictamen, la Comisión expresaba su firme convicción en relación a la necesidad de adaptación de las instituciones político-administrativas de los pueblos "a su situación y circunstancias". Con ello los ponentes reconocían la necesidad de una organización jurídico-política distinta para las colonias, en función de sus numerosas peculiaridades. Finalmente, el 30 de junio las Cortes aprobaban las enmiendas introducidas a las proposiciones de Quiñones y sancionaban el texto elaborado por la Comisión ${ }^{31}$.

\section{El Proyecto Varela}

El conjunto de medidas propuestas por Quiñones en junio de 1822 no constituía por sí mismo un proyecto de reorganización del régimen colonial, pero sí suponía un primer paso hacia la reforma de éste. En este sentido, la aprobación de la mayoría de las propuestas presentadas por el diputado puertorriqueño abrió el camino para el planteamiento global de un nuevo modelo de organización colonial.

\footnotetext{
28 D.S.C, 10 de junio de 1822 , pp. 1812-1813.

29 D.S.C, 14 de junio de 1822 , p. 1899.

30 D.S.C, 29 de junio de 1822, pp. 2241-2242.

31 A.G.I, Sección 10, Ultramar, leg. 435.
} 
Con este objeto se produjo una convergencia entre Quiñones y el grupo reformista de la representación cubana en Cortes, cuyos máximos representantes eran Félix Varela y Leonardo Santos ${ }^{32}$.

Como resultado de esta colaboración los diputados antillanos presentaban el 15 de diciembre ante las Cortes una nueva proposición reclamando un modelo de organización especial para las colonias:

\begin{abstract}
"Siendo más urgente en Ultramar que en la Península una nueva instrucción para el gobierno económico-político de las provincias; no limitándose á las de Europa las que ha pedido S.M. y constando en la que se discute que no se extiende á Ultramar, pedimos á las Cortes que se nombre á una Comisión que teniendo esta instrucción a la vista, proponga lo que convenga á las circunstancias de aquellos países lejanos, según lo recomienda con oportunidad la Comisión de Diputaciones Provinciales"33.
\end{abstract}

El verdadero artífice de la propuesta fue el diputado cubano Félix Varela. El presbítero Varela era uno de los principales representantes de la tendencia exaltada del liberalismo en Cuba. Diputado en las Cortes de Cádiz y profesor de la Universidad de La Habana, ocupó una de las primeras cátedras de Derecho Constitucional creadas en España. Varela era, junto a José Agustín Caballero, con el que le unió una estrecha amistad, y el obispo Arizmendi de Puerto Rico, el máximo exponente del clero liberal antillano. Identificado con los planteamientos reformistas del sector mayoritario de la élite criolla, Varela trató de consensuar con la metrópoli la obtención de un mayor grado de participación de la élite antillana en el proceso de toma de decisiones que afectaran a las Antillas.

Disentimos de las tesis sostenidas por algunos historiadores cubanos, como E. Roig de Leuchsenring, que consideran que el Proyecto Varela constituía la primera fase de un plan independentista a corto plazo $^{34}$. Si se acepta que entre 1820 y 1823 Varela actuó como

32 En las elecciones de 1820 fueron elegidos diputados por Cuba el presbítero Félix Varela y el licenciado Leonardo Santos, como representantes de la facción liberal de la oligarquía cubana, en tanto que el médico Tomás Gener estaba más próximo al sector más conservador; vid. L. A. DE LA CUESTA: Constituciones cubanas desde 1812 hasta nuestros días, La Habana, Exilio, 1974, p. 29.

33 D.S.C, 15 de diciembre de 1822, p. 999.

34 E. ROIG DE LEUCHSENRING: "Algunas características del pensamiento político de Varela", en F. VARELA: Obras de Félix Varela y Morales, Universidad de la Habana, 1962,

R. I., $1997, \mathrm{n}^{\circ} 210$ 
portavoz de los sectores mayoritarios de la oligarquía cubana, lo que Leuchsenring admite, hay que concluir que la actividad política desarrollada por éste ante las Cámaras respondió a los objetivos de dicho grupo. Máxime cuando la misma tuvo lugar en sintonía con el resto de la representación reformista colonial. En este sentido, la mayoría de los especialistas coinciden en señalar que el objetivo inmediato de dichos sectores durante el Trienio se limitó a intentar obtener de la metrópoli una mayor participación en el proceso de toma de decisiones local, sin que en ningún momento llegara a plantearse un enfrentamiento con la metrópoli que hubiera podido desembocar en una guerra racial ${ }^{35}$.

De hecho, ni siquiera el proyecto presentado por Varela en 1823 puede ser calificado como autonomista, fórmula propugnada abiertamente por determinados sectores de la sociedad colonial, sino que por sus características debe ser englobarse dentro de lo que se ha venido en denominar asimilismo progresista.

Solo tras su exilio en 1823, condenado a muerte por la Audiencia de Sevilla por haber firmado el decreto que declaraba la incapacidad de Fernando VII para gobernar, comenzaría la evolución de Varela hacia el independentismo.

Una vez presentada la propuesta de los representantes antillanos, ésta pasó para su estudio a la Comisión de Ultramar de la que formaban parte los propios Varela y Quiñones ${ }^{36}$. El 16 de febrero de 1823 Varela; como ponente de la Comisión, presentaba un Proyecto de Instrucción para el gobierno económico-político de las provin-

vol .IX. También en L. LEAL: "Félix Varela and Liberal Thought", en A. OwEN (ed.): The Ibero-American Enlightenment, Urbana, UIP, pp. 238-242.

35 R. GuERra: Manual de la Historia de Cuba. Desde su descubrimiento hasta 1868, Madrid, Ediciones R, 1975, pp. 265-266; M. IZARD: Latinoamérica siglo XIX. Violencia, subdesarrollo y dependencia, Madrid, Síntesis, 1990, p. 159; G. BARALT: Esclavos rebeldes. Conspiraciones y sublevaciones de esclavos en Puerto Rico, 1795-1873, Río Piedras, Ed. Huracán, 1982, p. 57; C. DELGADO: Derecho y colonialismo. La trayectoria histórica del derecho puertorriqueño, Río Piedras, Edil, 1988, pp. 48-49.

36 Suscribieron la propuesta además de Leonardo Santos y Jose María Quiñones, Ramón Luis Escobedo, Pablo Santafé, José Meléndez y Manuel Vizmanos. E. RoIG DE LEUCHSENRING: La guerra libertadora cubana de los treinta años, 1868-1898, La Habana, Oficina del Historiador, 1968, pp. 1-3. 
cias de Ultramar ${ }^{37}$. La clausura de la legislatura extraordinaria días después demoraría la discusión de este proyecto en las Cortes, no volviendo a conocimiento de las mismas hasta el 4 de marzo de 1823 , fecha en la que tuvo lugar la segunda lectura, si bien el debate parlamentario no comenzaría hasta el 15 de dicho mes $^{38}$.

El Proyecto de Instrucción se componía de un extenso preámbulo y de 189 artículos, divididos en tres títulos. El primero (arts.1-79) estaba dedicado a la administración local, el segundo (arts.80-134) se ocupaba de la organización y funciones de las diputaciones provinciales, en tanto que el tercer título (arts.135-189) establecía las competencias concedidas a los jefes políticos en las colonias.

El Proyecto Varela, al igual que la Instrucción Gómez Becerra en el caso de la Península, constituía una ley de régimen local, que extendía a las colonias un nuevo modelo de organización provincial y municipal, basado en una interpretación descentralizadora del Título VI de la Constitución. Al mismo tiempo perfeccionaba, en el sentido de una mayor adaptación a las particulares condiciones de Ultramar, el funcionamiento de las instituciones establecidas de manera uniforme para la metrópoli y las colonias por la Instrucción de 1813.

Los principales aspectos de este proyecto eran los siguientes:

- La aplicación de criterios especiales para crear municipios en las colonias, dada la dispersión de la población en las Antillas.

- El alcance de las atribuciones concedidas a los jefes políticos y su mediatización por la diputación provincial. Fundamentalmente en orden al art.156 del Proyecto, que atribuía al jefe político un derecho de veto sobre la ejecución de las leyes, decretos u órdenes emanados de la metrópoli, si éste estimaba que eran contrarios a los intereses de la colonia. Extremo que se supeditaba al dictamen previo de la diputación provincial.

- Y finalmente, las amplias atribuciones otorgadas a las diputaciones provinciales en materia presupuestaria y de control legislativo.

\footnotetext{
37 F. VARela: Proyecto de Instrucción para el Gobierno Económico- Político de las Provincias de Ultramar, Madrid, Imp. de T. Alban y Co, 1823. También puede encontrarse dicho proyecto en A.G.I, Sección Indiferente, leg. 1523.

38 J. M. CHACON Y CALvo: El padre Varela y la autonomía colonial, La Habana, Molina y Cía, 1955, p. 9.

R. I., $1997, \mathrm{n}^{\circ}{ }^{2} 210$
} 
El principal interés de la propuesta de Varela radicaba en el papel otorgado a las diputaciones provinciales en los territorios de Ultramar, que transcendía el marco de competencias contemplado para las diputaciones provinciales peninsulares por la Ley Gómez Becerra. Así sucedía en materia presupuestaria, en donde se exigían para la diputación las amplias atribuciones contenidas en la propuesta presentada por Quiñones en junio del año anterior. En este ámbito habría que enclavar asimismo las excepcionales atribuciones concedidas a dicho organismo para armar buques, derivadas de la falta de una escuadra que garantizara las comunicaciones con la metrópoli y la defensa de estas colonias.

No obstante, la principal novedad era la posibilidad de ratificar o rechazar la suspensión de cualquier ley, decreto o providencia procedente de la metrópoli otorgada al jefe político por el art. 156. Dicha atribución dio lugar a un intenso debate, en el curso del cual algunos diputados metropolitanos argumentaron acertadamente que la aprobación del art. 156 confería a los gobernadores coloniales potestades muy superiores a las de los jefes políticos peninsulares. En este sentido se pronunciaba Argüelles, quién intentó circunscribir los efectos derivados de este artículo a las órdenes gubernativas emanadas del gobierno de la Nación, rechazando que las leyes aprobadas por las Cortes pudieran ser objeto de suspensión alguna ${ }^{39}$. En una línea similar el diputado Pedrávez sostenía que dicha disposición convertía a los jefes políticos en auténticos dictadores ${ }^{40}$. Similares argumentos fueron planteados a lo largo de la discusión por los diputados Becerra, Adán y Saavedra ${ }^{41}$. A favor de la misma se manifestó el diputado Jener, quien justificó su necesidad estableciendo una analogía con el sistema colonial inglés. Por su parte, Varela aducía la inexistencia de discrecionalidad en el uso de esta facultad, al estar condicionada a la previa consulta a la diputación ${ }^{42}$.

En suma, mediante este proyecto los diputados antillanos buscaban crear en las colonias un mecanismo político-administrativo que permitiera una participación indirecta de la oligarquía antillana en el

\footnotetext{
39 Diario de La Habana, 10 de julio de 1823.

40 D.S.C, 4 de marzo de 1823, p. 63.

41 D.S.C, 6 de marzo de 1823, pp. 65-66.

42 Ibid.
} 
proceso de toma de decisiones en materia colonial. Dotando a la misma de los medios necesarios para defender sus propios intereses frente a los de la metrópoli. Pese a las fuertes resistencias suscitadas el Proyecto sería aprobado por las Cortes el 31 de marzo ${ }^{43}$.

No obstante, la invasión de España por los "Cien mil hijos de San Luis" a principios de abril y el rápido derrumbamiento del régimen constitucional impedirían finalmente la aplicación del nuevo modelo de organización colonial.

Los modelos de organización colonial alternativos durante el Trienio Liberal: El proyecto autonomista de 1822.

Como hemos mencionado, la estrategia posibilista adoptada durante el Trienio por los parlamentarios antillanos estuvo dirigida a la obtención de un marco político-administrativo descentralizado para las Antillas que, en una primera etapa, no implicara conflictivas delegaciones del Poder Legislativo en los órganos periféricos de la Administración. Frente a esta actitud prudente, un sector de la oligarquía colonial comenzó a demandar la adopción de fórmulas abiertamente autonomistas.

En este contexto hay que enmarcar el proyecto de autonomía colonial elaborado en abril de 1822 por el regidor del Ayuntamiento de Matanzas, Gabriel Claudio de Zequeira ${ }^{44}$.

Zequeira, propietario de un ingenio en Matanzas era un representante genuino de la sacarocracia criolla. Su posición como regidor de un cabildo que constituía el centro urbano de una de las más importantes zonas azucareras cubanas indica su condición de portavoz de los principales grupos de interés de una región dominada por la gran propiedad esclavista.

El Proyecto Zequeira fue encargado el 1 de abril por una comisión del Ayuntamiento de Matanzas. Dicha comisión, integrada por los principales contribuyentes de la zona, hacendados azucareros fundamentalmente, había sido constituída para determinar cuales debían

43 D.S.C, 31 de marzo de 1823, pp. 193-198.

44 R. INFIESTA: "El proyecto de Constitución de Zequeira y los orígenes del autonomismo cubano", en Revista del Colegio de Abogados de La Habana, mayo-junio, (1938), pp. 260-287.

R. I., 1997, n. $^{\circ} 210$ 
ser las directrices que regirían la actuación de los diputados cubanos de este distrito en las Cortes. El proyecto, elaborado por el propio regidor con la ayuda de su secretario, fue presentado a la comisión el 12 de abril en forma de instrucciones para los diputados a Cortes por esta provincia, resultando inmediatamente aprobado por la misma ${ }^{45}$.

El Proyecto Zequeira, dado que la autonomía era incompatible con el marco político-administrativo sancionado por la Constitución de Cádiz propugnaba una amplia reforma constitucional. En este sentido, proponía la derogación o modificación de aquellos artículos de la Constitución que obstaculizaran la creación de un modelo de organización autonómico en las colonias, así como la incorporación al Texto de 1812 de un capítulo específico referido a las provincias de Ultramar. Con ello Zequeira planteaba por primera vez la necesidad de un estatuto jurídico-político particular para las colonias.

El autor justificaba en el preámbulo la necesidad de dichos cambios señalando las enormes diferencias existentes entre Ultramar y la Península, sobre todo en función de la heterogeneidad de la población de las colonias, diferencias que convertían la aplicación de la Constitución en Ultramar en un mero ejercicio teórico. A ello se unían las dificultades derivadas de la distancia, que para Zequeira determinaban la imposibilidad de administrar correctamente la colonia a través de gobernadores coloniales, que actuaban "a cerca de dos mil leguas de la fuente de la que emanan"46.

La reforma más importante del régimen constitucional afectaba al art. 1, para el que el regidor de Matanzas proponía una nueva redacción que distinguiera dos clases de ciudadanía dentro de la Monarquía: los ciudadanos españoles y los ciudadanos españoles americanos.

Las condiciones determinantes de la pertenencia al primer grupo serían establecidas por las Cortes de la Nación. En tanto que solo entrarían en la segunda categoría aquéllos que cumplieran los requisitos que, en su momento, estableciera una Asamblea colonial. Esta insólita distinción tenía como objetivo la concentración de todo el poder en manos del sector criollo de la oligarquía colonial, en

45 "Expediente (sic) sobre el proyecto de reforma de nuestra Constitución política escrito por Don Gabriel Claudio de Sequeira, vecino de Matanzas", en Boletín del Archivo Nacional, La Habana, vol. XXXIV, (1937), p. 13.

46 INFIESTA, [44] p. 265 
cuanto a que el Proyecto Zequeira limitaba el ejercicio de los derechos políticos en las colonias a la segunda clase de ciudadanos.

El gobierno autónomo colonial contemplado en el Proyecto constaba de un Ejecutivo, un Legislativo y un Tribunal Supremo independientes de los existentes en la metrópoli.

La dirección del Poder Ejecutivo se confiaba a una especie de representante de la metrópoli en la colonia nombrado por el Rey: el Real Conservador Constitucional. Esta autoridad tenía un carácter sumamente contradictorio, pues, por una parte, las Instrucciones le otorgaban una naturaleza análoga a la revestida por un embajador ante una potencia extranjera, en tanto que como capitán general, le correspondía el mando supremo de todas las fuerzas militares radicadas en la colonia. Asimismo el Real Conservador era el encargado de ejecutar las disposiciones legislativas emanadas de la Cámara y Gobierno coloniales, así como de nombrar y separar a propuesta de la Asamblea al presidente del Gabinete colonial, al que el Proyecto denominaba Secretario General.

Junto al anterior, el Proyecto Zequeira establecía un Gabinete colonial responsable ante el representante de la metrópoli y el Legislativo colonial. Éste era presidido por un Secretario General de Despacho y estaba integrado por cuatro secretarios de sección, correspondientes a Hacienda, Interior, Exterior y Guerra y Marina. Los secretarios de Despacho eran nombrados por la Asamblea, ante la cual respondían, en tanto que el Secretario General era propuesto por la Cámara, pero nombrado por el Real Conservador, que tenía la potestad de cesarlo en cualquier momento.

Asimismo, el Real Conservador estaba asistido por lo que inicialmente parecía una versión colonial del Consejo de Estado: el Recto Consejo Consultivo.

Junto al Recto Consejo, el Poder Legislativo residía en una Asamblea Española-Americana a la que el Proyecto atribuía a través de 21 cláusulas la mayoría de las facultades otorgadas por el art. 131 de la Constitución a las Cortes metropolitanas. En este sentido, las Cortes españolas solo conservaban respecto a las colonias antillanas las siguientes atribuciones: la determinación de la sucesión a la Corona, la firma de tratados internacionales de carácter político, la acuñación de moneda, la ordenación del sistema de pesas y medidas y el establecimiento de los planes generales de enseñanza. Ello su-

R. I., 1997, n. $^{\circ} 210$ 
ponía investir a la Asamblea de una competencia exclusiva sobre la legislación económica y administrativa referida a la colonia.

Finalmente, las Instrucciones establecían un sistema judicial independiente del metropolitano, integrado como éste por varios juzgados comarcales y una Audiencia territorial, si bien se dotaba a la Asamblea de la potestad para reorganizar dicho sistema de la manera que estimase más conveniente. Asimismo se creaba un Tribunal Supremo colonial, denominado Corte Decisiva de Justicia.

Los sectores de la sacarocracia cubana agrupados en torno a Zequeira pretendieron conseguir la adhesión de los hacendados de otros distritos. Con este objetivo los promotores del Proyecto intentaron constituir una Junta de Revisión, integrada por representantes de la totalidad de los distritos de la colonia, cuya función fuera el estudio de las reformas constitucionales propuestas por el Ayuntamiento de Matanzas, para su ampliación o enmienda. La intención de los promotores del Proyecto era recurrir a la vía abierta en la Constitución de 1812 por el derecho de petición, para constituir una delegación representativa de los principales intereses de la isla que presentara el Proyecto al Gobierno metropolitano ${ }^{47}$.

No obstante, el regidor cubano no pudo llevar a cabo sus proyectos. Nada más hacerse público el contenido de las Instrucciones, éstas fueron atacadas por los peninsulares residentes en La Habana, que consideraron a las mismas como el preludio de un proceso separatista. Sin embargo, para las autoridades coloniales resultaba más inquietante aún el intento de constituir una especie de asamblea, integrada por representantes de toda la colonia, para debatir la presentación de una propuesta a las Cortes metropolitanas.

Como se deduce del expediente instruído posteriormente fue esta última circunstancia la que determinó que las autoridades coloniales actuaran con suma celeridad. De esta manera, el gobernador de la isla ordenó la incautación inmediata del documento y la destitución y detención del propio Zequeira, aún antes de informar a la metrópoli. Paralelamente, la Audiencia de La Habana comenzó a instruir una causa que, sin embargo, culminó en una sentencia absolutoria el 11 de octubre de $1822^{48}$. Pese a ello, el manuscrito fue archivado por

\footnotetext{
47 El derecho de petición estaba reconocido por el art.373 de la Constitución de 1812. J. EstebAn: Las Constituciones de España, Madrid, Taurus, 1982, p. 95.

48 [45] p. 67
}

R. I., $1997, \mathrm{n}^{\circ} 210$ 
las autoridades coloniales que prohibieron la circulación de cualquier copia existente del mismo ${ }^{49}$.

Con ello el régimen liberal demostraba que, si bien estaba dispuesto a debatir la concesión de un nuevo estatuto jurídico-político a las Antillas e, incluso, a extender a las mismas un modelo de organización ampliamente descentralizado, no iba a tolerar la constitución en las mismas de ningún tipo de juntas o asambleas coloniales, que pudieran poner en cuestión la exclusiva potestad de las Cortes metropolitanas para legislar acerca de las colonias.

En el marco del Trienio este extremo no suponía marginar del proceso de toma de decisiones a las Antillas, ya que éstas estaban representadas en las Cortes metropolitanas. De ahí que el rechazo de la metrópoli a la iniciativa de los grandes propietarios esclavistas del distrito de Matanzas no despertara ningún tipo de reacción. La sacarocracia criolla, sumida en un proceso de vertiginoso desarrollo económico y obsesionada por el peligro latente de una revuelta esclava, antepuso la defensa de sus intereses económicos y de clase a la obtención de un mayor grado de autonomía política. Máxime, cuando en la década de los veinte aquellos no estaban aún subordinados a la consecución de ésta.

Through the study of the Constitutional Regime's response mechanisms vis-à-vis the final breaking up of the traditional Colonial model (1820-1823), the author analyzes the nature of the new relations model established by the Liberal Regime with the remmants of the Colonial Empire during the first three decades of the $19^{\text {th }}$ Century.

\footnotetext{
49 La sentencia sin embargo establecía que el Proyecto Zequeira era "uno de aquellos documentos que se debían graduar de peligrosos, si corrieran y anduvieran de mano en mano, particularmente en esta Isla". Por ello se producía el archivo del mismo, no consiguiendo Zequeira que se le devolviese pese a las reclamaciones que realizó al efecto. [45] p. 82.
}

R. I., $1997, \mathrm{n}^{\circ} 210$ 